\title{
Política Editorial da Revista Medicina - Ribeirão Preto
}

\section{Revista Medicina-Ribeirão Pre-
to é um importante veículo de
Educação Continuada, para mé-}

dicos e outros profissionais da Saúde, e serve como material didático para estudantes do Curso de Graduação. Nossa revista publica artigos originais, mas a maior parte de seu conteúdo é composta por artigos de revisão e, principalmente, pelos Simpósios, formalizados quando o Prof. Dr. Julio Cesar Voltarelli era o Editor.

No entanto, essa política editorial impede a indexação da Revista Medicina-Ribeirão Preto no MEDLINE, aspecto importante para a maioria dos nossos autores, composta por professores universitários, nesta época em que a maior parte dos processos de avaliação docente são baseados na produção científica.

Ao assumir a função de Editora, no final de 1998, planejei (apoiada por um dos editores associados, o Prof. Dr. Eurico Arruda Neto) iniciar o processo de indexação da revista no MEDLINE. Iniciamos, em 1999, com a publicação de um artigo em Inglês em cada número - primeiro passo no longo caminho a ser percorrido. No entanto, começaram as reclamações de que estávamos nos afastando dos objetivos da revista. Além disso, ainda em 1999, perdemos o principal pa- trocinador e os problemas financeiros levaram a um atraso sistemático na publicação de cada número - outro impedimento para a indexação.

Desistimos, mas a Comissão de Publicação continuou preocupada com o assunto. Assim, no final do ano passado, o Prof. Dr. Julio Cesar Voltarelli, a Sra. Valderes A.C. Falaschi e eu decidimos realizar levantamentos de opiniões de autores e referees sobre esse e outros aspectos da política editorial de nossa revista, cujos resultados detalhados publicaremos oportunamente. A maioria dos respondentes, tanto autores como referees, votou pela EDUCAÇÃO MÉDICA CONTINUADA, mesmo que isso impeça a indexação no MEDLINE.

Por coincidência, na época em que analisávamos as respostas, recebi da Sra. Maristela Medeiros Santos da Silva, secretária da Comissão de Cultura e Extensão da Faculdade de Medicina de Ribeirão Preto (FMRP), uma cópia do primeiro número da Revista Medicina - Ribeirão Preto, publicado em agosto de 1961, número composto por um equivalente dos nossos atuais Simpósios, sobre o tema HIPERTENSÃO ARTERIAL. Os diferentes capítulos foram escritos por destacados professores da FMRP: Eduardo Krieger, Hélio Lourenço de Oliveira, Fritz 
Köeberle, José Moura Gonçalves e Renato Godoy.

O Editor era o acadêmico Renato Keniti Kawano, mas editorial do primeiro número foi escrito pelo então presidente do Centro Acadêmico Rocha Lima, Fábio Leite Vichi, que apresenta a revista como " ... Nascida... da necessidade inadiável de apresentar à coletividade médica e médico-estudantil de nossa terra uma publicação que contivesse.... estudos da problemática médica seguindo até certo ponto a orientação da Faculdade de Medicina de Ribeirão Preto..." Portanto, com o apoio dos autores e dos referees, continuaremos tendo, como conteúdo central de nossa revista, a atualização em temas relevantes para o exercício da Medicina.

Profa.Dra. Maria de Lourdes Veronese Rodrigues Editora 